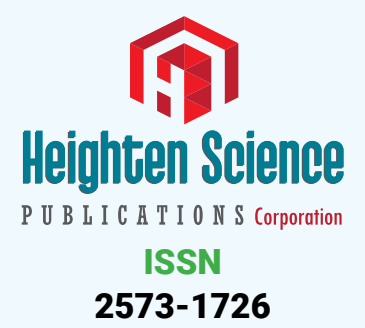

*Address for Correspondence: Ratko Pavlović, Faculty of Physical Education and Sport, University of East Sarajevo, Bosnia and Herzegovina, Email: pavlovicratko@yahoo.com

Submitted: 09 March 2018

Approved: 21 March 2018

Published: 22 March 2018

Copyright: @ 2018 Pavlović R, et al. This is an open access article distributed under the Creative Commons Attribution License, which permits unrestricted use, distribution, and reproduction in any medium, provided the original work is properly cited.

Keywords: Body mass index; Obesity; Development trend; Morphological status
Research Article

\section{The body composition analysis: Differences between students and the trend of their change}

\author{
Ratko Pavlović ${ }^{1 *}$, Zoran Radić2 ${ }^{2}$ Irina Juhas ${ }^{3}$ and Mensur Vrcić ${ }^{4}$ \\ ${ }^{1}$ Faculty of Physical Education and Sport, University of East Sarajevo, Bosnia and Herzegovina \\ ${ }^{2}$ Faculty of Physical Education, Sport and Health, University of Skopje, Macedonia \\ ${ }^{3}$ Faculty of Sport and Physical Education, University of Belgarde, Serbia \\ ${ }^{4}$ Faculty of Sport and Physical Education, University of Sarajevo, Bosnia and Herzegovina
}

\section{Abstract}

Anthropometric characteristics, represent one of the most important subsystems within the "system" of man, and which can be in affected by physical exercises in the direction of the desired transformation. Very often the anthropometric parameters (height and weight) are used in the assessment of the morphological status of an individual, and on the basis of the results of Body Mass Index (BMI) bring certain estimates and conclusions. BMI as a statistical measures, is used in many public health campaigns as an approximate measure of the ideal body mass and the degree of nutrition of a population. The main goal of the research was to determine and analyze differences in BMI parameters between male and female students, aged $18 \pm 0.5$ years, and determine the trend of changes. Using the T-test module, the obtained results confirmed that there are statistically significant differences in body height $(t=8,17 ; p<0.001)$ and body weight $(t=5,29$; $p<0.001)$, while in BMI values there are not statistically significant differences $(t=-0.68, p>0.001)$. Based on BMI values, a positive trend of somatic changes of both poles is evident.

\section{Introduction}

Being underweight, overweight, or obese during childhood and adolescence is associated with adverse health consequences throughout the life-course. Underweight among children and adolescents is associated with higher risk of infectious diseases, and for girls of childbearing age, is associated with adverse lifelong overweight and obesity [1,2]. Physical activity, even without reducing calorie intake, is a very effective method for reducing the risk of chronic illnesses, regardless of the degree of obesity $[3,4]$. In several recent studies [5] it has been established that the risk to the health of an obese person regularly engaged in some physical activity is no greater than the people with an ideal body mass index who are physically inactive.

It is less risky to have excess pounds on the hips and thighs than in the area of the abdomen, that is, the accumulation of fat deposits in that part increases the risk from heart disease and diabetes [6,7]. Booth, Chey, Wake, et al. [8], conducted a study in order to determine changes in the prevalence of overweight and obesity among young Australians (aged 7-15 years). The results showed that between 1985 and 1997, the prevalence of overweight and obese population has increased by $60-70 \%$, obesity 2-4 times and a combination of body weight and obesity has doubled. The findings were consistent for both sexes. For the period 1969 to 1985 there were no changes in the prevalence of overweight and obesity in girls but among boys the prevalence of overweight increased by $35 \%$, the prevalence of obesity has tripled, and the prevalence of overweight and obesity combined has increased by $60 \%$.The results of the six-year follow-up of 296 patients (aged 10 to 16 years in 2001 and 2007) by Ekblom, et al. 
[9], showed that there are no differences in BMI in sixteen year olds and low values of aerobic capacity and high BMI at age 10 years predicts obesity at the age of 16 . There was no difference in the prevalence of overweight plus obesity between the sample 2001 and 2007. As a conclusion was stated that normal weight and good aerobic fitness at 10 years old children reduce the risk of elevated BMI in relation to 16-year olds. The prevalence of obesity in children has been on the rise globally and currently constitutes a public health problem $[10,11]$.

The analysis of the results of anthropometric measurements enables the setting of norms, using standard methods and index methods. The evaluation of the morphological characteristics of the body's structure through the index has a limited, relative value and gives the examiner only a quick orientation on the body's development of the subjects and is primarily applied in adults [12]. At the end of the 1990s, BMI became popular amongst the general public, through various social health programs, which were mainly sponsored by Western governments - as an incentive to spread awareness of healthy lifestyles and healthy eating. BMI as a statistical measure is used in many public health campaigns as an approximate measure of ideal body weight. It is applicable to subjects between 18 and 65 years of age, but it is not suitable for children, pregnant women, athletes with high muscular masses and the elderly. Increased BMI values increase the risk of cardiovascular diseases (hypertension, myocardial infarction, and pulmonary diseases (sleep apnea sindrom). Body composition is an important indicator of the physical fitness and general health of athletes $[13,14]$ and today, it is often discussed on this topic in scientific literature. According to Claessens, Hlatky, Lefevre, \& Holdhaus [15], the shape of the body and its morphology, in addition to physical abilities, psychological characteristics and energy capacities of the system, is one of the main factors determining sports performance. Therefore, the diagnosis of body condition is often the subject of research, based on which a real insight into the current state of the defined population and possible negative or positive trends of growth and development over a certain period of time [16,17].

However, the basic critique of BMI as an indicator of child nutrition is that it does not directly measure the amount of fatty tissue. It would be possible for a teenager with well-developed muscles to describe himself as an overweight person, and a child with normal BMI to have excess fat on certain parts of the body. In children, simply weigh the masses and squares of height, i.e. BMI cannot be applied due to changes in bodybuilding during growth and development. The degree of development differs among different age, gender and ethnic groups. Therefore, the determination of obesity in children is done using special curves of the so-called. BMI percentiles that are adapted to the age and gender of the child. However, a large number of children with high BMI are indeed obese, but in order to be able to talk about obesity, other parameters such as WHR, WSR, etc. should be used. BMI percentiles are a clinical indicator used to compare one child to another child of the same age [18]. For example, if the BMI percentile for a child is 50th, this would mean that $50 \%$ of children of the same age and gender have BMI less than a measured child, and therefore $50 \%$ have higher BMI. Or, if BMI is percentile 60th, this means that $60 \%$ of children of the same age and gender have lower BMI. In connection to the above mentioned, this research was carried out with the aim of diagnosing somatic status of pupils of older school age and possible differences in quantitative indicators of somatic status, depending on sex, using BMI.

\section{Material and Methods}

The research covered the students of high school in Pale, East Sarajevo (Bosnia and Herzegovina). The sample consists of a total of 108 respondents, aged $18 \pm 0.5$ years, divided into two sub-classes: 50 male students (average height $186,40 \pm 12,11 \mathrm{~cm}$, body weight $74,64 \pm 12.31 \mathrm{~kg}$, BMI $21.46 \pm 3.64 \mathrm{~g} / \mathrm{m}^{2}$ ) and 58 female students (average height 170,12 $\pm 9,62$; average body weight $59,01 \pm 10,32 \mathrm{~kg}$; BMI $20,45 \pm 3,19 \mathrm{~kg} / \mathrm{m}^{2}$ ) who regularly attended physical education in secondary vocational school. The measurements were done in the physical education room of the secondary vocational 
school in Pale according to the IBP protocol. All students participated in measurement voluntarily.

Variables taken for the analysis of somatic status are:

1. Body height (height-cm),

2. Body weight (weight-kg),

3. Body Mass Index (BMI-kg/m²).

The body height was measured by an Anthropometer, while the body weight was measured by a digital scale. The data obtained in the research were processed in the statistical package SPSS Statistic 20.0. The results were obtained by descriptive statistics and the T-test for independent samples. For the assessment of students nutrition status, the $\mathrm{BMI}=\mathrm{kg} / \mathrm{m}^{2}$ and percentile range standard was applied. (NCHS, USA, 2000 and WHO). BMI is used to define the medical standard of obesity in many countries since the mid-1980s, and this method of assessment is also used in statistics of the World Health Organization (Table 1).

\section{Results}

Table 2 represents the numerical quantitative indicators of the physical status of the analyzed sample of students who provide the necessary information on their physical status. The average body height of the male students $(186,40 \mathrm{~cm})$ is considerably more than the female students $(170,12 \mathrm{~cm})$, which means $16 \mathrm{~cm}$ more in male than female. It is evident that the values of $\mathrm{CV} \%$ show a lower homogeneity of body height in female (5,65\%) compared to male students $(6,49 \%)$. Almost identical conclusions can be made in the values of the body weight of the analyzed sample. The average male students weight is about $75 \mathrm{~kg}$, which is $5 \mathrm{~kg}$ more than the female student's weight. It is also evident that the minimum body weight of both sexes is, deviation by $7 \mathrm{~kg}$, as opposed to the maximum weight where the difference is $15 \mathrm{~kg}$ (Table 2). Also, female students showed less homogeneity of results (CV\% 17,48) than male students (CV\% 16.49). Generally, in this variable, both sub-samples are defined with a significant low homogeneity, which is confirmed by the values of the range of results (Rang). Body Mass Index (BMI) as an indicator of the physical status of both sub-samples showed quantitatively quiet equal values (BMI male pupils $21.46 \mathrm{~kg} / \mathrm{m}^{2}$, BMI female pupil $20,45 \mathrm{~kg} / \mathrm{m}^{2}$, which is a significant homogeneity in relation to the average values of body height and body weight. However, by inspecting the minimum and maximum BMI values of both sexes, their range as well as coefficients of variation, it can be concluded that the sample is extremely heterogeneous. This is an indicator of the

Table 1: Values of the of BMI and Percentile range pupils (National Center for Health Statistics CDS Growth Charts: United States 2000).

\begin{tabular}{|c|c|c|}
\hline BMI $\mathbf{~ k g} / \mathbf{m}^{2}$ & Percentile range & Status \\
\hline$<18.5$ & $<5^{\text {th }}$ & Malnutrition \\
\hline $18.6-24.9$ & $5^{\text {th }}$ to $85^{\text {th }}$ & Normal nutrition \\
\hline $25-29.9$ & 85 to $<95^{\text {th }}$ & Excessive nutrition \\
\hline $30-34.9$ & $>95^{\text {th }}$ & Obesity I degree \\
\hline
\end{tabular}

\begin{tabular}{|c|c|c|c|c|c|c|c|}
\hline Variables & Gender & Mean & Min. & Max. & Rang & Std.Dev. & CV\% \\
\hline \multirow{2}{*}{ Body Height $(\mathrm{cm})$} & M & 186,40 & 165.00 & 199,00 & 34 & 12,11 & 6,49 \\
\hline & $\mathrm{F}$ & 170,12 & 150,00 & 185,00 & 35 & 9,62 & 5,65 \\
\hline \multirow{2}{*}{ Body Weight (kg) } & M & 74,64 & 57,34 & 93,12 & 35,78 & 12,31 & 16,49 \\
\hline & $\mathrm{F}$ & 59,01 & 50,78 & 78,42 & 27,64 & 10,32 & 17,48 \\
\hline \multirow[t]{2}{*}{$\mathrm{BMI}\left(\mathrm{kg} / \mathrm{m}^{2}\right)$} & M & 21.46 & 17.92 & 26.16 & 8,24 & 3,64 & 16,96 \\
\hline & $\mathrm{F}$ & 20,45 & 17,11 & 25,72 & 8,61 & 3,19 & 15,60 \\
\hline
\end{tabular}

Legend: Mean (mean value) Min. (minimum score); Max.(maximal score); Rang (range results); Std.Dev.(standard deviation) CV\% (coefficient of variation). 
unequal trend of growth and development, or un even physical status of students. To determine statistically significant differences between sexes, depending on numerical parameters for the assessment of body status, the $\mathrm{T}$-test for the significance level $\mathrm{p}<0.01$ was applied (Table 3). By inspecting the table, it is evident that there are significant differences in anthropometric measurements of body height $(t=8,17 ; p<0.001)$ and body weight $(t=5,29 ; p<0.001)$, unlike BMI where statistically significant difference between sexes is not evident. This is, however, an indicator of a period of where there are no major statistically significant morphological changes that characterize male and female population of the students, although it is evident that they exist.

\section{Discussion}

Obesity represents new world epidemics and is among the most serious health issues in Europe. In order to have a real chance to fight this phenomenon and keep it under control, all factors involved in this equation must get involved pragmatically for implementing an integrated management [19].

The research was carried out with the aim of diagnosing the somatic status of student's $18 \pm 0.5$ years old and the difference in quantitative indicators of somatic status depending on gender. Although the population of the student was defined with 108 subjects, final results determined this population and determined the trend of changes in the psychosomatic status of the body with the emphasis on changes in physical status. It is known that excessive nutrition in children and adolescents is a complex disorder whose incidence has increased significantly in recent years, which is a major health problem in the developed world [20]. It mostly occurs as a result of insufficient physical activity and sedentary lifestyle from the earliest age. Previous researches have suggested that regularity in physical activity, before any genetic factor, is associated with health. Development is now moving towards the advancement of technology, however, the performance and inclusion of children and adults in activities of a physical character are minimized. The assumption is that reduced physical activity has a major negative impact on the school population's psychomotor and psychosomatic effects. Studies have shown that the incidence of obesity is increasing in all age groups in both sexes. The more the index exceeds the scope of normal value, the greater the risk of the development of various diseases of the heart, diabetes and high blood pressure.BMI should be understood as a framework method because the actual state of health of a person should be assessed in a wider medical context [21]. Maintaining a normal body weight is one of the most important ways of keeping yourself healthy, and avoiding the risk of getting ill. Body weight and health state are in a interdependence relation. The health state can influence, in a positive or negative manner, the body weight, and vice-versa, any drop or increased in weight can influence, in a positive or negative manner, the health. An increase in body weight raises the risk for different health issues to appear, such as:cardio-vascular diseases, heart failure, arterial hypertension, myocardial infarction (heart attack), cerebrovascular accident (stroke), joint disorders, some types of diabetes, some types of cancer [19].

If we look at the individual contribution to this cumulative redistribution of the trend of physical changes (Figure 1), we would come to the conclusion that normal nutrition predominates in both sub-classes (88\% male and $83 \%$ female students), malnutrition

\begin{tabular}{|c|c|c|c|c|c|c|}
\hline \multirow[t]{2}{*}{ Variables } & \multirow[t]{2}{*}{ Gender } & \multirow[t]{2}{*}{ Mean \pm Std.Dev } & \multirow[t]{2}{*}{ t-value } & \multirow{2}{*}{$\begin{array}{c}p<0,001 \\
\text { Sig. }(2 \text {-tailed })\end{array}$} & \multicolumn{2}{|c|}{$\begin{array}{l}95 \% \text { Confidence Interval of the } \\
\text { Difference }\end{array}$} \\
\hline & & & & & Lower & Upper \\
\hline \multirow{2}{*}{$\begin{array}{l}\text { Body Height } \\
\text { (cm) }\end{array}$} & M & $186,40 \pm 12,11$ & \multirow{2}{*}{8.17} & \multirow{2}{*}{$0.000^{*}$} & \multirow{2}{*}{11.72} & \multirow{2}{*}{20.11} \\
\hline & $\mathrm{F}$ & $170,12 \pm 9,62$ & & & & \\
\hline \multirow{2}{*}{ Body Weight (kg) } & M & $74,64 \pm 12,31$ & \multirow{2}{*}{5.29} & \multirow{2}{*}{$0.000 *$} & \multirow{2}{*}{4.68} & \multirow{2}{*}{17.84} \\
\hline & $\mathrm{F}$ & $59,01 \pm 10,32$ & & & & \\
\hline \multirow[t]{2}{*}{ BMI $\left(\mathrm{kg} / \mathrm{m}^{2}\right)$} & M & $21.46 \pm 3,64$ & \multirow{2}{*}{0.68} & \multirow[b]{2}{*}{0.448} & \multirow{2}{*}{-2.38} & \multirow{2}{*}{3.66} \\
\hline & $\mathrm{F}$ & $20,45 \pm 3,19$ & & & & \\
\hline
\end{tabular}




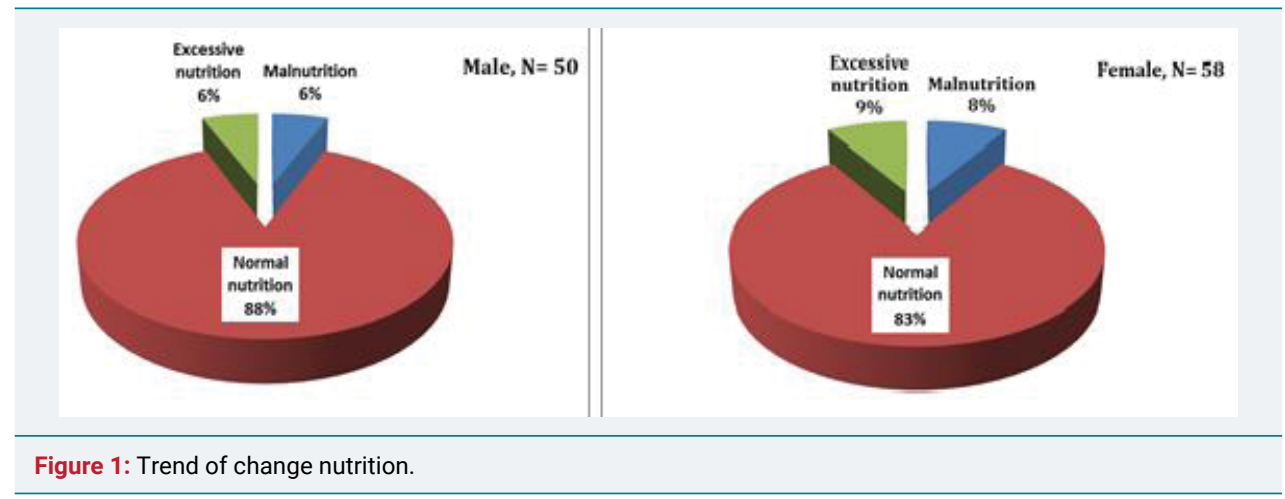

(6\% of male students and $8 \%$ of female students) and excessive nutrition ( 6 of male students and $9 \%$ of female students). These indicators are another confirmation that this 18-year-old age was not morphologically shaped and homogenized, since there are extremely small female (BMI $17,11 \mathrm{~kg} / \mathrm{m}^{2}$ ) and the increased values male (BMI 26,16kg/ $\mathrm{m}^{2}$ ) that are still in the phase of turbulent changes, and the possible consequence of extremely low or high values of defined anthropometric parameters, as a consequence of genetic modifications and the environment of an individual [22]. From the aspect of health diagnosis, BMI values and the degree of nutrition of our $6 \%$ male students and $9 \%$ of female students are in the category of increased nutrition, which is not alarming. However, if it is taken the students status, physical activity, body composition, bones, muscles then this is not a reliable conclusion. Perhaps one of these students is active in some sports such as athletics, martial sports where there is no ballast tissue, but an increase in BMI is an indicator of the active body mass, bones, muscles, extracellular fluid, etc. Also, these BMI values may have been predetermined much earlier, when they were about 10 years old. This is confirmed by the results of a six-year follow-up study of about 300 subjects aged 10-16 years, [9]) who have shown that high BMI at age 10 predicts obesity at the age of 16 , followed by decreased aerobic capacity. At every age, the average body height of girls is closer to the body height that they reach at maturity which is not the case with boys. Girls reach approximately half of the total body height (that they will reach in life) in their second year of life, and boys reach that when they are two and a half years old. On average, girls with burning acceleration, reach peak body mass at 10.7 years of age. Boys, on the other hand, achieve this at 12.6 years. The girls who matured at the average (expected) speed were 12.1 years old and boys 14.0 years at the time of reaching the peak of the body mass [23,24]. All these are reference indicators that sex differences are evident and have a corresponding growth trend, as confirmed by the research [22]. The results of our research are in accordance with the research of [25] which showed significant differences in terms of body height and body mass between male and female students. Here too, an imperative is imposed, without distinction in sex, that in addition to the medical examination of the individual, it is necessary to monitor and control the physical development in order to prevent the preservation of his health [26]. Another indicator which has not been taken into account in this study is waist circumference which can be a useful indicator of nutritional status in children and in adults [27]. Health risks of people with BMI over 25 are slightly smaller if their waist circumference is less than $101.6 \mathrm{~cm}$, a condition common for athletes exposed to considerable exercise load [28].In all BMI categories, people with the highest waist circumference have an increased tendency of hypertension, diabetes, increased blood fat and metabolic syndrome, compared to those with normal waist circumference [29].The question arises as to whether there would be significant differences in our sample in this parameter or not, as in the case of BMI, and would a different picture of this population be obtained? It is known that heredity plays an important, if not a key role, in the growth and development of the organism. In research on monozygotic and dizygotic twins [30], researchers have found a major influence of hereditary factors in the expression of body weight and 
BMI. They concluded that body weight and obesity were under strong genetic control, and that the environment in which a person grows has relatively little influence, which is contrary to the results of the study by [22]. Discovery of genes that are partially responsible for developing obesity supports this conclusion.

Nevertheless, numerous studies [31] confirmed the importance of physical activity as a means of preventing excessive obesity. In any case, whatever the results of some research are, physical activity, and especially sport, which is our personal choice, should be an integral part of our everyday life and an important factor in maintaining health, working capacity and balance in today's modern society, which unfortunately, high school students are increasingly avoiding.

\section{Conclusion}

The results of the current study on a sample of 108 students of both sexes, age $18 \pm 0.5$ years, confirmed the differences between male and female respondents in anthropometric parameters (height, $\mathrm{p}<0.001$, weight, $\mathrm{p}<0.001$ ), while in BMI values did not make a significant difference ( $p>0.001)$. This may be expected if the trend of growth and development of individual features and their acceleration and deceleration is known. What is encouraging, however, is the fact that about $85 \%$ of students of both sexes are in the normal nutrition category where BMI is male students 21.46; female students 20,45; malnutrition $6 \%$ of male students and $9 \%$ of female students and obese $6 \%$ of male students and $9 \%$ of female students. The results are not too alarming, but it is important to monitor and record their trend of changes, especially these $6 \%$ (males) and $9 \%$ (females) obese, taking care to prevent their growth trend.

As the main factor contributing to these indicators is today's way of life of children and young people, because today's development is moving towards the advancement of technology, however, the performance and inclusion of children and adults in physical activity is minimized. A lot of research is needed to understand the negative impact of obesity and express physical activity as an imperative that builds a healthy environment and population.

\section{References}

1. Ezzati M, Bentham J, di Cesare M, Bilano V, Cisneros JZ, et al. Worldwide trends in body mass index underweight, overweight and obesity from 1957 to 2016: a pooled analysis of 2416 population-based measurement studies in 128.9 milion children, adolescents and adults. The Lancet. 2017; 390: 2627-2642.

2. Singh AS, Mulder C, Twisk JW, van Mechelen W, Chinapaw MJ. Tracking of childhood overweight into adultthood: a sistematic review of the literature. Obesity Review. 2008; 9: 474-488. Ref.: https://goo.gl/RXQ9cj

3. Ross R, Freeman J, Janssen P. Exercise alone is an effective strategy for reducing obesity and related comorbidities. Exercise and Sport Science Review. 2000; 28: 165-170. Ref.: https://goo.gl/g7bG89

4. Department of Health and Human Services (USDHHS). Centers for Disease Control and Preventio, National Center for Chronic Disease Prevention and Health Promotion. (1996): Physical activity and Health: A report of the surgeon general. Atlanta, GA: U.S. Department of health and Human Services,Government Printing Office.

5. Haskell WL, Lee IM, Pate RR, Powell KE, Blair SN, et al. Physical activiti and public health:Updated recommendation for adults from the American College of Sports Medicine and the American Heart Association. Medicine and Science in Sports and Exercise. 2007; 39: 1423-1434. Ref.: https://goo.gl/jy3Nmq

6. Wickelgren I. Obesity: How big a problem? Science. 1998; 280: 1364-1367. Ref.: https://goo.gl/9nzh51

7. Zeigler E. Filer R. Present knowledge in nutrition (7. edition), 2000. Washington, DC: International Life Sciences Press.

8. Boot LM, Chey T, Wake M, Norton K, Hesketh $\mathrm{K}$, et al. Change in the prevalence of overweight and obesity among young Australians, 1969-1997. Am J Clin Nutr. 2003; 77: 29-36. Ref.: https://goo.gl/5znijX

9. Ekblom BÖ, Ekblom BEA, Ekblom TB. Trends in body mass in Swedish adolescents between 2001 and 2007. Acta Pædiatrica. 2009; 9: 519-522. Ref.: https://goo.gl/SgUwLJ 
10. Sadoh WE, Sadoh AE, Onyiriuaka AN. Physical activity, body mass index and bloond pressure in primary school pupils attending private school. Afr. Health Sci. 2016; 16: 947-953. Ref.: https://goo.gl/jyx1yj

11. Wang Y, Lobstein T. Worldwide trends in childhood overweight and obesity. Int J PediatrObes. 2006; 1: 11-25. Ref.: https://goo.gl/qXawwk

12. Pavlović R, Raković A, Mihajlović I, Petrović B, Stanković D. Analysis of the morphological status students by applying of different methods of the index. SPORT SCIENCE-International Scientific Journal on Kinesiology. 2015; 1: 30-39. Ref.: https://goo.gl/gygdo8

13. Warner ER, Fornetti WC, Jallo JJ, Pivarnik JM. A Skinfold Model to Predict Fat Free Mass in Female Athletes. Journal Athletic Training. 2004; 39: 259-262. Ref.: https://goo.gl/keULbD

14. Van der Ploeg GE, Gunn SM, Withers RT, Modra AC. Use of anthropometric variables to predict relative body fat determined by a four-compartment body composition model. Eur J ClinNutr. 2003; 57: 1009-1016. Ref.: https://goo.gl/T9qCdw

15. Claessens AL, Hlatky S, Lefevre J, Holdhaus $H$. The role of anthropometric characteristics in modern pentathlon performance in female athletes. J Sports Sci. 1994; 12: 391-401. Ref.: https://goo.gl/mYLsRx

16. Sorensen L, Smolander J, Louhevara V, Korhonene O, Oja P. Physical activity, fitness and body composition of Finnish police officers: A 15-year follow-up study. Occupational Medicine. 2000; 50: 3-10. Ref.: https://goo.gl/ABDx2d

17. Dopsaj M, Milošević M, Vučković G, Blagojević M, Mudrić R. Diagnostics of the body mass index of students of the Police Academy. Sport Medicine. 2005; 5: 180-191.

18. Vasić Z, Vidović S, Šuščević D, Karan Ž, Lončar M, et al. Anthropometric analysis of elementary school pupils in rural areas. Journal of the Anthropologycal Society of Serbia. 2011; 46: 95-102. Ref.: https://goo.gl/379XQA

19. Balint T, Dobrescu T, Rata M, Cristuta A. Research regarding the assessment of a body's normal size by using the body mass index. Gymnasium. 2010; 9: 14-20. Ref.: https://goo.gl/JrHHY9

20. Al-Nakeeb Y, Duncan MJ, Lyons M, Woodfield L. Body fatness and physical activity levels of young children. Annals of human Biology. 2007; 34: 1-12. Ref.: https://goo.gl/cZxpov

21. Pavlović R, Bjelica B, Bonacin D, Pržulj R, Stojanović N. Differences in motor abilities manifestations depending on quantitative parameters of Body mass index of students. European Journal of Physical Education and Sport Science. 2017; 3: 64-81. Ref.: https://goo.gl/6FQfuY

22. Koziel S, Gomula A. Variation of height and BMI within school classes in 14-year-old children. AnthropolAnz. 2017; 74: 77-80. Ref.: https://goo.gl/z3F14M

23. Abernethy B, Hanrahan JS, Kipers V, Mackinnon TL, Pandy GM. Biophysical Basis of Human Movement. 2012. Beograd. DATASTATUS (Translate).

24. Hagg U, Taranger J. Height and height velocity in early, average, and late maturers followed to the age of 25: A prospective longitudinal study of Swedishurban children from birth to adulthood. Annals of human Biology. 1991; 18: 47-56. Ref.: https://goo.gl/axBWXA

25. Šegregur D, Kuhar V, Parađzik P. Antropometrical, motorical and functional abilites of first-grade secondary school students. Hrvatski Športskomedicinski Vjesnik. 2010; 25: 67-74.

26. Sallis JF, McKenzie TL, Conway TL, Elder JP, Prochaska JJ, et al. Environmental interventions for eating and physical activity: a randomized controlled trial in middle schools. Am J Prev Med. 2003; 24: 209-217. Ref.: https://goo.gl/7fzmFa

27. Katmarzyk RT, Srinivasan SR, Chen W, Malina RM, Bouchard C, et al. Body mass Index, waist circumference, and clustering of cardiovascular disease risik factors in a biracial sample of children and adolescents. Pediatrics. 2004; 114: 198-205. Ref.: https://goo.gl/43Xnnq

28. Sharkey JB, Gaskill ES. Fitness and Health. 2008. Beograd: Data Status (Translate).

29. Janssen I, Katzmarezyk P, Ross R. Body mass index, waist circumference, and health risk. Archives of Internal Medicine. 2002; 162: 2074-2079. Ref.: https://goo.gl/N8SyTV

30. Stunkard A, Foch T, Hrubec V. A twin study of human obesity. Journal of the American Medica Association.1986; 256: 51-54.

31. Cho M, Kim JY. Changes in physical fitness and body composition according to the physical activities of Korean adolescents. J Exerc Rehabil. 2017; 13: 568-572. 